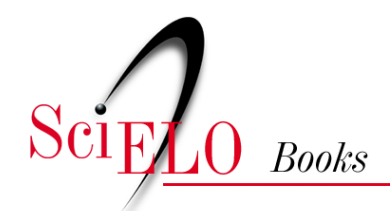

\title{
Reinvenções poéticas pelo humor
}

\author{
Marília Rothier Cardoso
}

\section{SciELO Books / SciELO Livros / SciELO Libros}

CARDOSO, M.R. Reinvenções poéticas pelo humor. In: WERKEMA, A.S., ROCHA, F.C.D., and OLIVEIRA, L.D., eds. Literatura brasileira em foco VIII: outras formas de escrita [online]. Rio de Janeiro: EdUERJ, 2018, pp. 14-26. ISBN 978-85-7511-487-2.

https://doi.org/10.7476/9788575114872.0002.

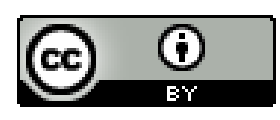

All the contents of this work, except where otherwise noted, is licensed under a Creative Commons Attribution 4.0 International license.

Todo o conteúdo deste trabalho, exceto quando houver ressalva, é publicado sob a licença Creative Commons Atribição $\underline{4.0}$.

Todo el contenido de esta obra, excepto donde se indique lo contrario, está bajo licencia de la licencia Creative Commons $\underline{\text { Reconocimento } 4.0 .}$. 
Marília Rothier Cardoso

Reinvenções poéticas pelo humor 
Há alguns meses, fiz parte do grupo de convidados para um banquete em torno da poesia. Os anfitriões - poetas, performers e pesquisadores de poesia - recomendaram-nos ler poemas e preparar falas sobre nossas leituras. Este contraponto entre comida e palavras lembra a estratégia do filósofo Gilles Deleuze de discutir a "lógica do sentido", explorando a dualidade corpos/linguagem. Conforme a história da filosofia, os antigos serviram-se dos elementos materiais para instrumentalizar o pensamento, prenderam-se à profundidade, onde os corpos se transformam e se afetam uns aos outros: Heráclito formulou o conceito de tempo observando o movimento da água; já Parmênides inspirou-se na terra e no fogo como causa principal na constituição do cosmos. Numa etapa mais sofisticada do ato de conhecer, quando se desejou distinguir o mythos do logos, Platão empreendeu o movimento ascensional e determinou que os significados se prendessem às ideias transcendentes, de que os corpos do mundo não passavam de cópias. Por seu turno, os sofistas - em particular, os estoicos - empreenderam aventura mais arriscada, experimentaram a superfície como espaço da operação da doação de sentido. Trataram suas elucubrações como "acontecimentos", resultados de gestos deslizantes, na linha horizontal que limita, 
abaixo, os seres corpóreos, e acima, a linguagem, formada de extrasseres incorpóreos. Nessa linha estreita e instigante, é que Deleuze surpreende o "sentido", resultado paradoxal de quase-causas que, negando as operações da profundidade (designação e manifestação) e da altura (significação), afirmam o sentido. Para tornar contemporâneo esse legado epistemológico dos antigos, Deleuze evoca poetas modernos às voltas com as "séries da oralidade" - comer/falar. De um lado, traz Artaud, preso às profundezas do corpo, escrevendo como se mastigasse as palavras. De outro, considera Lewis Carroll, que trouxe suas personagens fantásticas para a superfície do espelho. Aí, não há devoração nem transformações. O nonsense da superfície constrói-se na reversibilidade das direções e na simultaneidade dos tempos.

Imagino que os jovens poetas, reunidos neste "banquete experimental", mesmo que não radicalizem sua relação com a tradição poética, nem se dediquem aos jogos de questionamento das significações estabelecidas, pratiquem os exercícios do humor, resistindo às agressões sombrias do presente. Vou-me arriscar propondo minha leitura de trechos escolhidos de alguns deles.

Interessado em escapar das convenções do senso comum e do bom senso, Lucas Matos também se dedica à invenção poética e performatiza a dualidade falar-comer: 
em pedaços

[...]

CONVIDEI UM PAR de amigos para o almoço

comprei berinjelas batatas

baroas para o purê pimentões

gengibre abóbora chegaram

enquanto eu ainda estava

na cozinha mãos de cebola e alho

ele trouxe um kiwi congelado

para suco ou sorvete os dois

ficaram na cozinha sentados

no chão ou debruçados na parede

conversando enquanto eu

terminava então fui tomar

banho depois comemos na sala

[...]

foi que ele lembrou

da história do avô de uma

amiga da amiga

que sem ter com

quem conversar telefonava

para serviços de atendimento

ao cliente para reclamar

de coisas como o aumento

do preço do pacote de pão

[...]

comemos bis e tentamos

tomar o suco de kiwi na hora

da sobremesa quando eles se

foram já estava escuro

e tinha muita louça para lavar (Matos, jun. 2017, pp. 29-30). 
Não se pode dizer que a amostra dos "pedaços" de poesia, tratando de comida e conversa, seja tão atraída pelas vísceras profundas que chegue a mastigar as palavras. No entanto, sem que tenha suprimido letras ou insistido em sons guturais, o leitor do poema é captado, inevitavelmente, por sua materialidade. $\mathrm{O}$ corte dos versos insiste no atropelo da sintaxe e separa sujeito de verbo, adjetivo de substantivo, verbo de complemento. Aqui, a aparente experiência de tratar o banal com a solenidade da arte desenvolve o procedimento ambíguo de desafiar a gramática, mesmo usando ordem direta e obedecendo aos regimes nominais e verbais. $\mathrm{O}$ coloquial mais rasteiro se complexifica em estranhamento, impedindo que o poema aconteça apenas oralmente. Sua inscrição na página torna-se obrigatória. O leitor é conduzido até quase a vertigem (o poema é longo) do fundamento material, onde os tipos se inscrevem na página, para as alturas da significação, que os grupos de letras produzem. Em voz alta ou silenciosamente, a leitura exige saltos constantes, tornando inviável a suposta tranquilidade de uma conversa durante o almoço e demonstrando, na prática, a impossibilidade de que as relações verbais se processem inconscientemente como a digestão. Assim, revela-se, tão sub-reptícia quanto perigosa, a distância entre o corpo e a linguagem, entre a designação e a expressão. O rigor cruel da construção do poema fica patente na justaposição dos "pedaços” de que se compõe: a conversa afável dos amigos que se visitam, trocando gentilezas, é desmentida pelo assunto de que tratam. A troca de mensagens, levando ou não a consequências positivas, só se dá em situações previstas pela lei ou pelos interesses comerciais. A escuta atenta que se espera, ao invés de uma tendência afetiva, vem de uma previsão mecânica num texto decorado por um profissional. Atento às tecnologias características do presente, Lucas Matos percebe que o humor negro independe de 
monstros violentos. Ao contrário, surge, veemente e necessário, nas circunstâncias mais comuns, nas frases mais diretas, completas e corriqueiras.

No mesmo volume 2 dos Cadernos do CEP, Ana Carolina Assis usa estratégias composicionais bem mais complicadas com o objetivo paralelo de experimentar a tensão entre os corpos e a linguagem. Com um título em feminino - "Mariana" - que tanto pode nomear uma menina ou uma mulher como um local no campo ou na cidade, vai traçando uma cena familiar e surreal. Seu exercício poético fascina e ameaça. É um poema “em pânico". E foi o próprio Murilo Mendes que garantiu: "o pânico é muitas vezes necessário" (Mendes, 2010, p. 37).

\section{Mariana}

a criança

olhos de gafanhoto

água às vezes deixa um cheiro de

bicho nas coisas

carne pouca pra tanto lodo

bicho - água que escorre dentro d'água

a garganta

groselha rala das lancheiras

caramelo viscoso de rio

surpresa crosta das cartilhas

estufado piso e farpa dos móveis

as coxas - malha puída de nova

que uma barba crespa

rasga

e carrega nos ombros 
parecem bombas a mãe dizia parecem bombas de sucção a mãe dizia os ralos regurgitando carne e atraso pros jantares devolvendo a gelatina das coisas exigindo dos tijolos o que eles não tinham parecem sangue do meu sangue a mãe dizia (Assis, jun. 2017, pp. 6-7).

O vocabulário escolhido para compor a cena remete, sem dúvida, à profundidade dos corpos. As frases - ora quebradas em versos muito curtos, ora encadeando-se em versos longos - indicam invasões, contaminações. Predominam elementos líquidos ou pastosos que levam ao apodrecimento, à decadência. $\mathrm{O}$ ambiente turvo contrasta com a (possível) vitalidade da personagem - "criança”. No entanto, seus objetos escolares ("lancheira", "cartilhas") estão à beira de deteriorar-se na umidade reinante. Até a proximidade entre os corpos humanos mostra-se agressiva: as "coxas", a "malha" rasgam-se em contato com a "barba crespa". Sílabas iniciadas por gutural espalham-se pelo poema, assim como as matérias viscosas ("caramelo", "gelatina", "sangue") se insinuam por entre os sólidos. Esse espaço, tanto quanto a criança que vive nele com sua família, enfrenta o perigo do atolamento ou da sucção. Em sua crueza, a vida é uma ameaça.

$\mathrm{O}$ atropelo das imagens, que compõem o movimento das cenas, evoca o não senso das entranhas, da profundidade. No entanto, o corte e a distribuição dos versos na página não desfiguram as expressões aí inscritas. Também, diferente do que se espera, as indicações de tempo, em conjunto, fogem a qualquer cronologia, por isso, subvertem o processo das evoluções ou involuções. Coincidem, inesperadamente, o tempo do apodrecimento das partes da casa com o tempo da rotina familiar - a ida para a escola, os "jantares" —, como se ações e paixões surgissem em ritmo de "devir louco". 
O contraste, evidente, entre os movimentos no espaço e o tempo das personagens parece deslocar o poema das indistinções profundas às singularidades deslizantes da superfície. Assim, poder-se-ia captar a instauração de efeitos paradoxais que resultam em humor. O pathos trágico reverte-se em apreensão crítica.

Trabalho artístico equivalente, onde as séries da oralidade comer/falar —, parecendo tendentes à predominância da primeira, acabam mostrando deslocamentos entre uma e outra, encontra-se em poema assinado por Rafael Zacca, no $1 .^{\circ}$ volume dos Cadernos do CEP:

\title{
tarda
}

Uma barca leva uma pedra

ou um sol de flores engastadas

em poeira

sobre a pele oleosa

\author{
um aceno \\ como sabão das crianças \\ em tardes \\ de primavera a primeira
}

apenas uma

pedra

que se abre

dura lembrança das crianças que abrem

cocos e lambuzam já não se sabe

se o queixo ou as mãos

pequenas. 
Amargo é retornar
a gordura à boca

mas não seriam

amargos

os poemas de

agora postos

sobre a mesa e as conversas

meladas

como amoras

na boca (Zacca, maio 2017, pp. 24-5).

Tão distante da coloquialidade cotidiana quanto a escrita de Ana Carolina, esta experiência artística também se produz em certo clima solene e desconfortável. Desenha frases que se aproximam da textura incômoda dos corpos em busca do prazer eventualmente possível na prática da poesia. Embora sem polarizar os dois espaços - o que se poderia tomar como a significação sublime da arte, em oposição à designação dos corpos com suas vísceras profundas -, o poema se desloca entre um e outro, a partir da perspectiva do tempo. O emprego de uma forma verbal como título constitui procedimento incomum e sugere uma leitura atenta ao que escapa às convenções. Sendo assim, a cronologia - dependente das significações estabelecidas - cede lugar à materialidade do vocábulo "tarda", desencadeador de assonâncias: as vogais abertas ("tarda", "barca", "leva”, "pedra”, "sol", "engastadas"), que, ao longo do texto, retornam em alternância com vogais fechadas e nasais. Paralelamente, as aliterações (em dentais, bilabiais e sibilantes) compõem uma imagem sonora potente, superposta às imagens visuais propostas pela articulação - marca- 
damente surrealista - entre os significados do vocabulário empregado. Parece que a superposição das imagens sonoras - reforçadas pela distribuição gráfica da página - às imagens plásticas opera o duplo movimento de descida das formas estéticas ideais e de subida dos sons e texturas pegajosas (oleosidade, "poeira", consistência "melada" que "lambuza"), instalando a escrita na superfície. Pode-se, então, perceber, na reiteração do signo "crianças" - com suas conotações de "jogo" e "brincadeira" -, um deslizamento, alegre e cruel, entre o gosto (amargo, gorduroso), que sobe das entranhas à boca, e as "lembranças", "poemas" e "conversas", lançados "sobre a mesa". Seguindo a orientação deleuziana, para além dos efeitos trágicos ou irônicos, esse deslizamento na superfície produz o humor paradoxal. Se os efeitos desse jogo intrincado "tardam", é porque se mostram extemporâneos.

Ainda no $1 .^{\circ}$ volume dos Cadernos do CEP, Maria Isabel Iorio inclui uma releitura - em homenagem? como paródia para descarte? num retorno desviante? - de um clássico drummondiano ${ }^{1}$ do humor modernista:

virilha

João era Teresa que era Raimundo

que era Maria que era Joaquim que era Lili

que não era ninguém.

1 QUADRILHA

João amava Teresa que amava Raimundo

que amava Maria que amava Joaquim que amava Lili que não amava ninguém.

João foi pra os Estados Unidos, Teresa para o convento,

Raimundo morreu de desastre, Maria ficou para tia,

Joaquim suicidou-se e Lili casou com J. Pinto Fernandes

que não tinha entrado na história (Drummond de Andrade, (1930) 1967, p. 69) 
João foi para os Estados Unidos, Teresa para as estatísticas, Raimundo morreu de pancada, Maria ficou para a fila, Joaquim suicidou-se e Lili ainda é chamada de J. Pinto Fernandes como toda essa gente que não entra na História (Iorio, maio 2017, p. 19).

Apresentando-se como estratégia experimental distante de "Mariana" e "tarda" - escritas de um humor fantástico, que investe contra o real histórico por meio de um tenso contraste crítico "virilha" tende a aproximar-se de "em pedaços", radicalizando o emprego do coloquial através da repetição em diferença de um texto antológico, que qualquer leitor é capaz de reconhecer. Se Drummond parodiava a lírica romântica, num gesto, que hoje nos soa como simples inversão, Maria Isabel Iorio é, possivelmente, mais séria e desabusada, pois homenageia o mestre subvertendo suas referências ético-sociais. Se, no contemporâneo, acirram-se as questões de gênero, etnia, identidade e pertencimento a uma nacionalidade, $o$ novo poema afirma que não se trata mais de uma "quadrilha", onde se troca de par, mas de uma virada mais complexa. O título "virilha" aponta para significados múltiplos: parte do corpo geralmente sexualizada, reversão sem objetivo definido, devir constante em lugar de metamorfose ou até mesmo (com grafia ligeiramente modificada) uma das combinações de sílabas que, a certa altura, nomearam a personagem de "Desenredo" de Guimarães Rosa, aquela que mudava de amores e se mostrava outra a cada parágrafo da estória. Enquanto as vanguardas exigiam liberdade de escolha e ampliação do conceito de arte, a violência do cotidiano atual, nos vários níveis de relações, exige que se flexibilizem os critérios de identificação e se reivindiquem serviços públicos e visibilidade para os habitantes das diferen- 
tes margens. Os traços irônicos, que eventualmente ainda restassem na "Quadrilha" moderna, foram "virados" no humor cruel, onde as histórias (estórias) se confundem com a "História".

$\mathrm{Na}$ Lógica do sentido, que me serviu de referência, buscam-se linhas de fuga à tradição do pensamento ocidental. Por isso mesmo, seu interesse se volta para o "humor", distinto da "ironia", trabalhada pela escrita dos filósofos canônicos. Em suas três versões - socrática, clássica e romântica - a "ironia” volta-se para as alturas transcendentes (em contraponto à profundidade dos corpos), apegada, em cada período, a uma das dimensões da proposição: significação, designação e manifestação. Escapa a esta linhagem o "sábio estoico", que empreende a "dupla destituição da altura e da profundidade em proveito da superfície". "[...] Mais tarde e em outro contexto", pode-se acompanhar a trajetória do Zen "-contra as profundidades bramânicas e as altitudes búdicas. Os célebres problemas-provas, as perguntas-respostas, os koan, demonstram o absurdo das significações, mostram o não-senso das designações" (Deleuze, 1974, p. 139). Companheiro do sábio estoico e do cultor do Zen, o poeta especialmente desde Mallarmé - também empreende ascensões e descidas em direção à "superfície" da linguagem, onde acontece a "aventura do humor". 


\section{Referências}

ASSIS, Ana Carolina de. "Mariana". In CHACAL et al. Cadernos do CEP, v. 2 Rio de Janeiro, jun. 2017.

DELEUZE, Gilles. Lógica do sentido. Trad. Luiz Roberto Salinas Fortes. São Paulo: Perspectiva, 1974.

DRUMMONDDEANDRADE, Carlos. Obracompleta. Rio de Janeiro: Aguilar, 1967.

IORIO, Maria Isabel. "virilha”. In CHACAL et al. Cadernos do CEP, v. 1, Rio de Janeiro, maio 2017.

MATOS, Lucas. “em pedaços”. In CHACAL etal. Cadernos do CEP, v.2, Rio de Janeiro, jun. 2017.

MENDES, Murilo. In LIMA, Jorge de. A pintura em pânico; fotomontagens. Rio de Janeiro: Caixa Cultural, 2010.

ZACCA, Rafael. "tarda". In CHACAL et al. Cadernos do CEP, v. 1, Rio de Janeiro, maio 2017. 